\title{
PEMBERDAYAAN KAUM IBU DALAM PELAYANAN DI GKSI SEKTOR KUALA BEHE KECAMATAN KUALA BEHE KABUPATEN LANDAK KALIMANTAN BARAT
}

\author{
Malik, ${ }^{1}$ Rikarni Zai, ${ }^{2}$ Sandi Ziliwu ${ }^{3}$, Lelis Sakerebau ${ }^{4}$ \\ Sekolah Tinggi Teologi Injili Arastamar (SETIA) Jakarta \\ malikbambangan@sttsetia.ac.id
}

\begin{abstract}
Education for the community in general is often dominated by male groups, this also has an impact on their involvement in church services, even though talking about education applies to all genders, both men and women. But the reality that is often found in the church is that mothers often do not get the opportunity to serve compared to men. That is why the purpose of this research is to find out the active role of mothers in Church Services in the GKSI Kuala Behe Sector, Kuala Behe District, Landak Regency, West Kalimantan. The method used is by conducting interviews and serving the congregation by involving women to serve in their congregations. As a result of this study, it was found that mothers in the Kuala Behe sector had the ability to serve in theology. The conclusion of the study is that mothers have the same position to devote themselves to serving in the GKSI congregation in the Kuala Behe Sector.
\end{abstract}

Keywords: Theology, Women, Ministry, Church; Role

\begin{abstract}
ABSTRAK
Pendidikan bagi masyarakat pada umumnya seringkali didominasi oleh kelompok pria, hal ini berdampak pula pada keterlibatan mereka dalam pelayanan jemaat, padahal berbicara tentang pendidikan berlaku bagi semua gender, baik laki-laki maupun perempuan. Namun kenyataan yang sering didapati dalam jemaat kaum ibu sering tidak mendapat peluang untuk melayani dibanding dengan kaum laki-laki. Itulah sebabnya tujuan penelitian ini adalah untuk mengetahui peran aktif kaum ibu dalam Pelayanan Gereja di GKSI Sektor Kuala Behe, Kecamatan Kuala Behe, kabupaten Landak Kalimantan Barat. Metode yang digunakan adalah dengan mengadakan wawancara serta pelayanan kepada jemaat dengan melibatkan kaum wanita untuk melayani di jemaat mereka. Sebagai hasil dari penelitian ini, didapati bahwa kaum ibu di sektor Kuala Behe, memiliki kemampuan untuk melayani dalam bidang Teologi. Kesimpulan dari penelitian adalah kaum ibu memiliki kedudukan yang sama untuk mengabdikan diri dalam pelayanan di jemaat GKSI Sektor Kuala Behe.
\end{abstract}

Kata Kunci: Teologi, Perempuan, Pelayanan, Gereja; Peranan

\section{PENDAHULUAN}

Memasuki era globalisasi ini, begitupun dalam dunia emansipasi wanita, mengharapkan agar dapat mengangkat harkat dan martabat wanita setaraf dengan kaum pria. Perjuangan ini juga telah dimulai sejak pertengan abad ke-19. Dengan demikian strata sosial wanita dan pria dapat dikatakan sama derajatnya di masyarakat dalam segala bidang. Hal inilah yang menyebabkan munculnya teologi feminis, yang didominasi oleh kaum wanita. Menanggapi latar belakang munculnya teologi feminis ini, Malik Bambangan menyatakan bahwa, Gerakan kaum perempuan ini muncul dengan dilatarbelakangi oleh dasar kerinduan kaum perempuan untuk menilai dan mempertimbangkan serta memberikan tempat atau kedudukan bagi kaum perempuan baik dalam

\footnotetext{
${ }^{1}$ Dosen Prodi Teologi Sekolah Tinggi Teologi Injili Arastamar (SETIA) Jakarta

${ }^{2}$ Mahasiswa Prodi Teologi Sekolah Tinggi Teologi Injili Arastamar (SETIA) Jakarta

${ }^{3}$ Mahasiswa Prodi Teologi Sekolah Tinggi Teologi Injili Arastamar (SETIA) Jakarta

${ }^{4}$ Mahasiswa Prodi Teologi Sekolah Tinggi Teologi Injili Arastamar (SETIA) Jakarta
} 
masyarakat secara umum maupun dalam gereja secara khusus. Teologi feminis ini di prakarsai oleh Elisabeth Parmentier dari Prancis pada tahun 1960. Dengan membaca ulang Alkitab tanpa menutupi peran perempuan yang juga bisa berperan dengan baik dalam gereja.

Dalam dunia emansipasi wanita, mengharapkan agar dapat mengangkat harkat dan martabat perempuan setaraf dengan kaum laki laki. Dengan demikian strata sosial wanita dan pria dapat dikatakan sama derajatnya dalam segala bidang. Hal ini dipicu oleh adanya diskriminasi gender yang ditujukan kepada kaum wanita dalam beberapa dekade terkahir ini. Wanita merasa dihina dan rendahkan oleh kaum pria dalam melaksanakan tugasnya. McGrath menyatakan bahwa, pandangan yang merendahkan wanita bukan hanya ada di luar kekristenan. Di dalam gereja sendiri, tragisnya, sering kali wanita dipandang sebagai harta milik, objek yang membahayakan, dan yang paling keras adalah, wanita dinilai tidak mampu menjadi gambar Allah sehingga mereka dilarang untuk menjadi pemimpin, pengkhotbah dan pengajar dalam ibadah maupun pelayanan di gereja. Perlakuan gereja terhadap kaum wanita seperti ini memang tidak terjadi secara menyeluruh dalam gereja Kristen pada masa kini, itulah sebabnya berbicara mengenai peranan wanita dalam gereja masih menjadi perdebatan teologis yang belum tuntas.

Dominasi kaum pria yang, anehnya, telah berlangsung secara mengglobal jauh sebelum era globalisasi, telah menggoreskan luka yang dalam di hati banyak wanita. John Stott menggambarkan kondisi ini dengan kata-kata yang cukup tajam demikian, for there is no doubt that in many cultures women have habitually been despised and demeaned by men. They have often been treated as mere playthings and sex objects, as unpaid cooks, housekeepers and childminders, and as brainless simpletons incapable of engaging in rational discussion. Their gifts have been unappreciated, their personality smothered, their freedom curtailed, and their service in some areas exploited, in others refused. Tidak mengherankan jika timbul berbagai reaksi dari kaum wanita, mulai dari yang sekadar memendam rasa tidak puas hingga yang berani bersuara bahkan yang lebih ekstrim, memberontak terhadap tatanan yang telah berurat berakar di masyarakat. Tidak heran pula jika di berbagai penjuru dunia kita akan menemukan gerakan kaum wanita yang dikenal dengan istilah "feminisme," suatu gerakan yang dilandasi oleh kesadaran kaum wanita bahwa mereka adalah makhluk yang Tuhan ciptakan sederajat dengan pria.

\section{Metode Penelitian}

Locus penelitian ini adalah di Desa Terapang dan desa Kedama kecamatan Kuala Behe kabupaten Landak Kalimantan Barat. Setelah mendapatkan surat tugas dari SETIA Jakarta, maka langkah pertama adalah mengadakan pelaporan diri sekaligus sosialisasi tentang maksud dan tujuan penelitian ini kepada pemerintah setempat, BPW GKSI Landak dan Pengurus Sektor GKSI Kuala Behe. Kemudian tim mengadakan sosialisasi dan komunikasi kepada Jemaat secara khusus jemaat GKSI Bakoi dan Bati. Alasan dua desa ini karena letak kedua jemaat tersebut berdekatan namun dalam wailayah desa yang berbeda. Pada akhirnya menyusun hasil kegiatan penelitian dalam bentuk artikel ini.

\section{PEMBAHASAN}

Dalam Perjanjian Lama wanita diciptakan sehakekat dengan pria serta mendapat panggilan dan peran yang berbeda namun sama-sama penting di hadapan Allah, maka Allah menciptakan manusia itu menurut gambar Allah diciptakan-Nya dia; laki laki dan perempuan diciptakan-Nya mereka (Kej. 1:26-27). Hal ini mengandung arti bahwa wanita diciptakan sebagai penolong yang sepadan dengan laki laki. Tindakan Allah dalam menciptakan benda-benda langit, tumbuhtumbuhan dan binatang sangat berbeda dengan tindakan Allah pada waktu menciptakan manusia. Karena manusia diciptakan melalui tangan Allah sendiri menurut rupa dan gambar Allah sedangkan ciptaan yang lainnya sebelum Allah menciptakan manusia, hanya dengan firman maka jadilah demikian (Kej. 1:3-25). Demikian juga dalam pelaksanan tugas pelayanan di gereja, baik wanita maupun pria memiliki kedudukan yang sama untuk mengambil bagian melayani. Dalam Alkitab (Perjanjian Lama dan Perjanjian Baru) juga memuat tentang berita-berita penting yang dilakukan oleh wanita atas panggilan Tuhan bagi mereka. Mereka melakukan tugas tersebut 
dengan meyakininya sebagai panggilan Allah baginya sama seperti panggilan Allah kepada kaum pria.

Dalam berbagai kesempatan banyak wanita yang berjuang untuk mendapatkan penghargaan yang sama dengan kaum pria. Dalam dunia sekularpun juga mendambakan hal yang sama yakni penghargaan kepada kaum wanita. Stanton dalam Apa Itu Teologi, menyatakan bahwa, adalah penting bagi para perempuan untuk mengambil bagian dalam pendidikan teologi, serta memegang peranan dalam kepemimpinan gereja dan masyarakat. Djamal Irwan juga menegaskan bahwa, sudah waktunya sekarang mengategorikan tokoh wanita Indonesia ke dalam beberapa kategori seperti tokoh pendidikan, politik, eksekutif, yudikatif, jurnalistik, lingkungan, pertanian, ekonomi, agama dan lain lain. Itu artinya bahwa kaum wanita memiliki peranan yang sama dengan kaum laki-laki dalam segala bidang.

Dengan mencermati hal tersebut di atas, maka hal itu pula memberi indikasi kepada wanita Kristen yang ada di Indonesia untuk berpartisipasi dalam segala bidang. Oleh sebab itu wanita Kristen Indonesia perlu melihat bahwa kebebasan yang semakin terbuka itu bisa menjadi ancaman.Dikatakan sebagai ancaman karena hal kebebasan itu justru akan menjauhkan wanita dari panggilan yang dimaksudkan oleh Allah, jika wanita menjadi terlalu sibuk,dan menganggapnya sebagai persaingan dengan pria. Larry Keefauver menyatakan bahwa, pelayanan dimulai dengan hati bukan dengan penampilan. Motivasi yang dicemari keinginan untuk tampil atau memperoleh kedudukan akan menghasilkan hasil yang salah atau perselisihan, perpecahan, luka batin dan kepedihan. Sebagai akibat dari diskriminasi kaum wanita di Indonesia sebagai contoh seperti pada pemaparan Lumintang dalam mengutip Hasiholan menyatakan, bahwa Demikian juga dengan pemilu tahun 1999, masih ada kelompok yang mengeluarkan fatwa mengharamkan perempuan menjadi presiden. Hal ini benar-benar melanggar konvensi internasional tentang penghapusan segala bentuk kekerasan terhadap perempuan yang ikut dan hak untuk dipilih dalam pemilihan umum.

Purnomo menyatakan bahwa karena perbedaan interpretasi-interpretasi terhadap ayatayat tertentu dalam Alkitab, maka selama beberapa abad yang lalu kaum wanita telah menderita banyak diskriminasi dalam pelayanan gereja. Perlu dipahami bahwa dosa memang telah merusak, tidak saja relasi manusia dengan Allah, tetapi juga relasi manusia dengan sesamanya, termasuk di dalamnya relasi yang berkaitan dengan peran posisi pria dan wanita dalam tatanan gereja keluarga, masyarakat dan negara. Manusia diciptakan berbeda dari binatang dan dari segala mahluk yang lain, karena dia dijadikan menurut gambar dan rupa Allah. Sedangkan F.L. Bakler menjelaskan bahwa manusia mempunyai hubungan khusus dengan Allah, dengan sesama manusia, dan dengan ciptaan makhluk yang lainnya. Itu artinya bahwa Pria dan wanita dalam pandangan Baker adalah sama di hadapan Allah.

\section{Jenis-jenis pelayanan kaum wanita dalam gereja .}

\section{a. Sekolah Minggu.}

Sekolah minggu sering dianggap hanya salah satu kegiatan pelayanan yang melibatkan hamba Tuhan dan jemaat menjadi satu tim. Tetapi jika dilihat dari potensi pelayanan, sekolah minggu sama seperti sebuah gereja yang disebut dengan gereja di dalam gereja. Setiap komisi pelayanan harus diperlakukan seperti sebuah gereja dimana berbagai pelayanan bisa dilakukan di dalamnya, seperti kunjungan penggembalaan anak-anak, penginjilan anak-anak, camp anak-anak, sekolah Alkitab liburan, retreat, paduan suara anakanak, perpustakaan sekolah minggu anak-anak, dan masih banyak yang bisa dilakukan dalam pelayanan sekolah minggu.

b. Persekutuan Wanita jemaat.

Wanita jemaat dibutuhkan untuk menangani pelayanan wanita, maka yang bisa dilakukan adalah sebagai berikut:

1) Menjadi penanggunjawab persekutuan wanita dan memikirkan bagaimana mengembangkan pelayanan ini. Ia harus membaca buku-buku rohani yang berkaitan dengan pelayanan kaum wanita agar bisa mendelegasikan tugas pelayanan ini.

2) Menyelenggarakan pelayanan rutin wanita.

3) Berkhotbah dan mengajar serta memikirkan pola pelayanan terbaik untuk wanita.

4) Mengadakan kunjungan mengunjungi para anggota wanita dan pendatang baru.

5) Mengadakan perkunjungan mengunjungi mereka yang sakit, malas, dan sebagainya. 
6) Mengadakan rapat persekutuan wanita.

7) Menggembalakan setiap wanita dan menunjukkan perhatiannya.

8) Menyusun program retreat dan seminar sesuai dengan kebutuhan wanita.

9) Menyusun topik-topik khotbah sesuai dengan kebutuhan wanita.

10) Mendidik anggota wanita untuk bisa berdoa dan bersaat teduh.

11) Menyusun kelompok Pendalaman Alkitab wanita menurut kebutuhan dan wilayahnya.

12) Bertanggungjawab dalam pelayanan paduan suara wanita.

c. Penginjilan.

Dalam penginjilan ini dibutuhkan partisipasi jemaat untuk turut terlibat dalam belajar dan melayani. Banyak hamba Tuhan dan pendeta gagal dalam hal penginjilan, apalagi para guru Injil yang memegang gelar sebagai guru Injil tetapi tidak pernah melakukan penginjilan. Di bawah ini dijelaskan beberapa tugas yang bisa dilakukan oleh wanita dalam penginjilan:

1) Mengadakan pelatihan-pelatihan rutin untuk mendidik jemaat agar bisa melakukan penginjilan pribadi. Program ini tidak bisa dilakukan satu atau dua kali tetapi harus terus menerus dan berkala. Untuk bisa menginjili maka orang harus bisa memastikan siapa yang harus dibina yaitu mereka yang sudah sungguh-sungguh percaya Yesus, jika tidak, ia tidak layak menjadi tim penginjilan karena Tuhan tidak akan pernah memakai orang yang belum percaya menjadi pemberita Injil. orang tidak akan pernah bisa membawa orang lain percaya pada Yesus.

2) Membuat seminar penginjilan.

3) Menyusun dan menyelenggarakan tim penginjilan setiap minggu.

4) Merencanakan dan mengadakan malam penginjilan atau yang sering dikenal dengan KKR. Program ini akan effektif jika penginjilan mingguan dan harian berjalan dengan baik. Tujuan dari malam penginjilan atau KKR dimaksudkan untuk menjangkau jiwa-jiwa yang belum percaya pada Yesus dan bukan mempengaruhi jemaat gereja lain pindah ke gereja saudara.

5) Melakukan penginjilan rutin untuk orang-orang tertentu.

d. Kunjungan

Pelayanan kunjungan merupakan pelayanan penting dalam gereja. Pelayanan ini bukan hanya sekedar berkunjung dan bertanya kenapa tidak hadir dan sebagainya tetapi ada berita firman Allah yang bisa dibagikan untuk menguatkan dan menegur jemaat yang dikunjungi. Pelayanan kunjungan juga sering diasumsikan hanya ditujukan kepada mereka yang tidak hadir dalam ibadah, sakit atau malas. Kunjungan bukan hanya bagi mereka yang termasuk dalam kategori sakit dan tidak hadir dalam ibadah tetapi pelayanan kunjungan adalah penggembalaan dan kepedulian gereja terhadap jemaat. Seringkali gereja sibuk dalam pelayanan kunjungan tetapi hanya ditujukan bagi jemaat yang tidak hadir ibadah minggu. Kategori yang bisa dilakukan dalam pelayanan perkunjungan:

1) Memotivasi jemaat ikut terlibat dalam tim kunjungan secara bergilir.

2) Membuat jadwal kunjangan mingguan dan harian.

3) Membuat program pelatiahan tim kunjungan. Seseorang yang berperan sebagai tim kunjungan harus bisa memberikan nasihat dari firman Allah.

4) Mengunjungi mereka yang sakit, lemah, malas dan lainnya.

5) Mengarahkan jemaat yang dikunjungi bergabung dengan persekutuan yang ada.

6) Membantu tim kunjungan khusus bagi pendatang baru dalam gereja. Jika tertarik, pendatang baru bisa diarahkan mengikuti kelas-kelas khusus pembinaan kerohanian dan 
kelas katekisasi bagi mereka yang sudah percaya serta ingin mengalihkan keanggotaannya.

7) Kunjungan bisa dilakukan setiap hari untuk pembinaan dan pendewasaan rohani jemaat.

e. Pendalaman Alkitab (PA)

PA (Pendalaman Alkitab) merupakan jenis pelayanan yang selalu diabaikan diberbagai gereja. Pelayanan ini sangat penting dalam membina pertumbuhan kerohanian jemaat. Kelompok PA bisa dilakukan untuk semua kalangan: wanita menikah, wanita tidak menikah, muda-mudi, dan sebagainya. Setiap jenis profesi bisa menjadi satu kelompok pendalaman Alkitab yang dipimpin oleh pelayan Tuhan. Jika anggotanya laki-laki maka dimpin oleh laki-laki dan jika anggotanya perempuan bisa dimpin oleh perempuan. Seorang pemimpin harus bisa menggerakkan dan memobilisasi jemaat untuk bersama-sama mengerjakan talenta masing-masing dalam pelayanan. Apa yang diutarakan di atas hanya sekedar contoh dalam pelayanan gereja dimana perempuan memiliki peran yang penting didalamnya. Berkhotbah dan mengajar dari mimbar gereja bukanlah satu-satunya jenis pelayanan di dalam gereja. Yang terpenting bagi seorang pelayan yang dipanggil Allah adalah menggenapi panggilan yang diberikan Tuhan kepadanya.

\section{Tantangan wanita dalam melaksanakan pelayanan.}

Menanggapi ketidakpuasan kaum wanita terhadap sikap Gereja yang masih menomorduakan kaum wanita, maka wanita merasa diperlakukan sebagai kaum kelas dua dalam Gereja. Hal ini tampak jelas bahwa Gereja tidak dapat menerima wanita ditahbiskan menjadi imam. Kaum wanita tidak bisa mendapat jabatan pemimpin dan terlibat dalam keputusan resmi gereja. Inilah yang menjadi polemik utama yang masih sampai sekarang merongrong gereja. Kalau di cermati tentang stereotip dan slogan-slogan gerakan yang harus di tanggung kaum wanita sepanjang sejarah, misalnya makhluk yang lemah, harus berdiam diri, penakut, tidak percaya diri, makhluk kelas dua. Kemudian apakah Roh Kudus telah memperbaharui, wanita-wanita masa kini menjadi pemelihara dan pemberi kehidupan. Wanita di perhadapkan dengan situasi dan tantangan masa sekarang.

\section{Peranan wanita dalam pelayanan gerejawi di GKSI Sektor Kuala Behe}

a. Pandangan GKSI tentang peranan wanita dalam pelayanan gerejawi.

Integritas merupakan salah satu tolok ukur penting perilaku seseorang. Integritas merupakan batu uji karakter dan penjelas sejarah kehidupan personal dan psikologis yang menjadi sumber perilaku dan sikap moral dan etis seseorang. Karena itu, kalau seorang pelayan kehilangan integritasnya, gereja dan segala pelayannya sedang berada dalam bahaya.

Pengaruh sekularisme, pluralisme, dan juga relativisme telah merasuk mempengaruhi kehidupan jemaat dan pelayannya. Hal ini memicu munculnya berbagai peristiwa yang menyangkut kehidupan para pendeta Gereja Kristen Setia Indonesia, yang berawal dari persoalan finansial, seksualitas perselingkuhan, perceraian, pendeta yang memanipulasi jabatannya untuk menambah pendapatan, bahkan sampai memicu konflik membangun permusuhan dengan jemaat, yang bisa berujung pada perpecahan gereja. Memang, aspek sosial-politik juga turut mempengaruhi. Namun, kalau para pelayan mempunyai arah hidup yang jelas tentang diri dan pelayanannya, kemungkinan besar, semua hal yang ada tidak menjadi sumber permasalahan, sebaliknya akan dipakai sebagai sarana memperkuat spritualitas, moralitas, sehingga mampu mengambil sikap etis yang membangun dan bukan sebaliknya, menghancurkan.

Gereja Kristen Setia Indonesia sudah mampu merumuskan nilai-nilai yang bisa dikembangkan sebagai dasar menyusun panduan pelayanan yang lebih baik. Mungkin, nilainilai itu bisa menjadi dasar bagi pembaruan Gereja Kristen Setia Indonesia, sehingga apa yang tertulis dalam Roma 12:2, menjadi nyata: Janganlah kamu menjadi serupa dengan dunia ini, tetapi berubahlah oleh pembaruan budimu, sehingga kamu dapat membedakan manakah 
kehendak Allah yakni apa yang baik, yang berkenan kepada Allah dan yang sempurna. Menanggapi hal tersebut, maka Trull dan Carter menyerukan bahwa, Pentingnya sebuah peraturan yang memandu perilaku para pelayan Gereja atau code of conduct. Namun panduan perilaku lain tidak harus menghilangkan kreativitas dan pengembangan otoritas kependetaan para pendeta atau pelayan gereja. Hal itu tidak bisa terlalu rinci dan kaku, atau sebaliknya longgar dan tak ada petunjuk jelas. Mungkin lebih tepat adalah sebuah prinsip yang bisa dikembangkan oleh para pelayan gereja secara kreatif.

Sekalipun demikian juga harus mengakui bahwa di beberapa gereja lokal semangat klerusisme masih cukup dominan. Khusus jemaat-jemaat di pedesaan dimana sebagian besar pendidikan formal warga masih belum memadai, pemberdayaan warga jemaat dewasa ini belum menampakkan kemajuan. Tetapi kasus-kasus ini kiranya tidak mengurangi pengakuan kita terhadap peranan warga jemaat dewasa dalam pertumbuhan dan perkembangan kekristenan.

b. Tantangan-tantangan gereja dalam meningkatkan peran kaum wanita.

1) Tantangan yang sering dihadapi terjadi dalam pergaulan remaja putri yang tidak terkontrol sehingga salah pergaulan akhirnya jarang ke gereja.

2) Remaja putri yang menikah dengan pasangan yang tidak seiman akhirnya tidak ke gereja dan larut pada agama lain.

3) Ibu-ibu muda yang dengan berbagai alasan tidak aktif dalam kegiatan gereja karena kesibukan, anak dan keluarga.

4) Ibu-ibu yang minder sehingga enggan mengikuti kegiatan gerejawi seperti PA dan juga kegiatan wanita lainnya.

c. Upaya Peningkatan peranan wanita dalam pelayanan gerejawi.

1) Mengikuti seminar tentang wanita yang di adakan oleh Sektor, wilayah, Sinode maupun yang di adakan oleh gereja lain.

2) Mengadakan pelatihan kreativitas, memasak dan usaha cari dana untuk kas gereja.

3) Gereja memfasilitasi dalam setiap kegiatan wanita baik berupa uang maupun sarana lain yang di butuhkan.

4) Mengadakan retreat ke luar daerah.

5) Mengadakan Paskah wisata ke lokasi wisata pantai ataupun gunung.

6) Mengadakan Natal wisata ke lokasi wisata

HASIL

1. Kaum wanita diharapkan dapat menemukan kembali kekuatan dan keberanian dari Allah untuk mengambil bagian secara menyeluruh dan utuh pada tugas pelayanan kristiani. Dan ini juga bukan hal yang mudah, namun penuh resiko dan tanggungjawab serta bersedia menanggung konsekuensi apapun yang menimpa dirinya, maka akan mengalami berkat berkat khusus yang selama berabad abad tersembunyi dan tidak diakui.

2. Wanita diajak untuk dapat menghadapi dan mengatasi situasi yang tidak menguntungkan bagi dirinya secara positif dan bijaksana, namun juga dapat terus maju dan berkarya walaupun di hadapkan dengan situasidan kondisi yang serba sulit.

3. Wanita kalau ingin maju harus berperan tidak perlu minta pengakuan dari pihak lain, khususnya pria, karena pengakuan terhadap eksistensi wanita akan datang dengan sendirinya seiring dengan peran wanita yang nyata di tengah gereja dan masyarakat.

4. Wanita tertantang untuk berkompetisi secara positif dengan pria, kompetisi ini bukan untuk mengalahkan atau merendahkan pihak lain, namun lebih pada tantangan upaya peningkatan kualitas.

5. Untuk merubah dan memperbaharui image dan stereotip bahwa wanita lemah dan tidak mampu, sangat dianjurkan supaya wanita berani berperan dalam segala hal. Wanita hendaknya melihat dan memakai kesempatan menggunakan peluang sekecil apapun yang ada, sehingga bisa memanfaatkan kelebihan yang dimilikinya untuk berperan aktif dalam masyarakat.

6. Gereja tentunya harus tanggap dan memberi tempat kepada kaum wanita. Kaum wanita hendaknya mendapat pengakuan dan penghargaan sepenuhnya dalam Gereja. Sehingga dalam karyanya, Gereja menyediakan pelayanan yang lebih melibatkan kaum wanita.

7. Pemahaman Alkitab yang diadakan di rumah ibu-ibu akan tumbuh dengan baik karena mereka mengambil bagian dalam mengabarkan firman Allah kepada tetangga mereka, kepada teman- 
teman mereka atau rekan sekerja mereka. Wanita Kristen menghadapi tantangan untuk membawa firman Allah di dalam rumah tangga dan dari rumah tangganya kepada rumah tangga orang lain. Inilah satu cara penginjilan yang berhasil.

8. Pembatasan terhadap peran kaum wanita dalam gereja ini masih dirasakan imbasnya sampai sekarang. Namun lepas dari itu semua, perkembangan gereja saat ini mulai banyak menempatkan peran kaum wanita dalam pelayanan gereja bila dibandingkan situasi gereja masa lampu yang masih tertutup bagi mereka. Sekarang cukup banyak wanita yang sudah terlibat dalam tugas dan pelayanan, terlebih perannya dalam tugas-tugas pastoral.

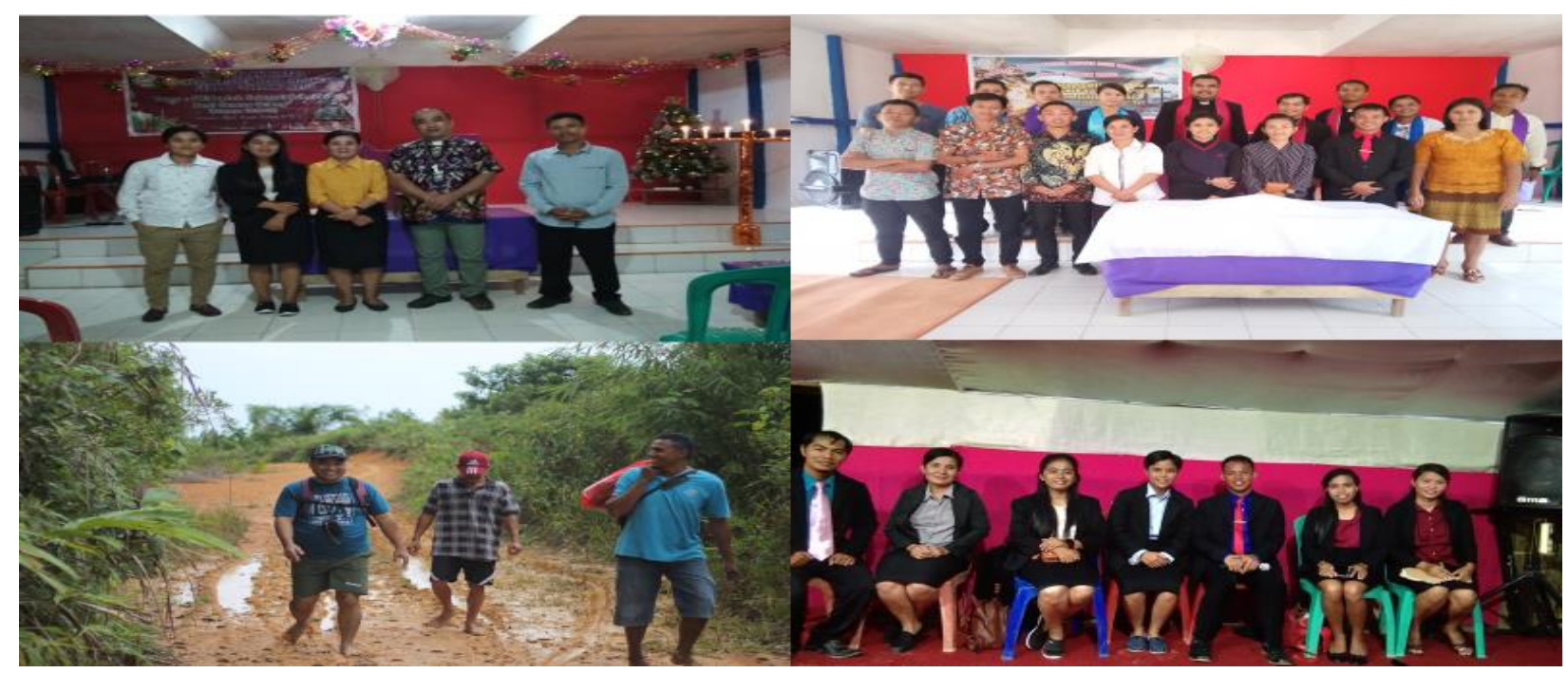

KESIMPULAN DAN SARAN

Berdasarkan pengamatan peneliti selama melayani di Gereja Kristen Setia Indonesia sektor Kuala Behe, kondisi jemaat kaum wanita membutuhkan bimbingan pelayanan yang praktis dan ekonomis untuk pertumbuhan rohani mereka. Adapun yang perlu dirumuskan adalah metode pelayanan kaum wanita dalam kegiatan gerejawi secara sehat dan berkesinambungan khususnya ibu-ibu muda agar mampu terlibat dalam pelayanan Gereja.

\section{Ucapan Terima Kasih}

1. Terima kasih Institusi Sekolah Tinggi Teologi Injili Arastamar (SETIA) Jakarta melalui Pembantu Ketua IV (LPMI \& PKM) Ev. Tony Salurante, M.Pd.K., MA.

2. Terima kasih kepada BPS GKSI

3. Terima kasih kepada BPW GKSI Landak

4. Terima kasih kepada Sektor Kuala Behe

5. Terima kasih kepada pemerintah Kuala Behe

\section{Kepustakaan}

Bakker, F.L., Sejarah Kerajaan Allah: Perjanjian Lama. Jakarta: BPK Gunung Mulia,1990

Bambangan, Malik, Pembimbing kedalam Teologi Sistematika I- Bahan Ajar. Purwokerto: STT

Diakonos, 2015

Drewes, B.F. dan Mojau, Julianus, Apa Itu Teologi. Jakarta: BPK GM, 2011

Hasilon, Dheyna, Politik dan Perempuan. Depok: Koekoesan, 2007.

Irwan, Zoeraini Djamal, Besarnya Ekploitasi Perempuan dan Lingkungan di Indonesia. Jakarta:

Kompas Gramedia, 2009.

Keefauver,Larry, 77 Kebenaran yang Hakiki dalam Pelayanan. Jakarta: Media Injil Kerajaan, 1990

Lumintang, Stevri Indra, Re-Indonesiasi Bangsa. Batu: Departemen Multi-Media YPPII, 2009

Mangentang, Matheus, Visi dan Misi SETIA. Jakarta: DELIMA, 2016.

McGrath, Alister E. ed., The Blackwell Encyclopaedia of Modern Christian Thought.

Oxford:Blackwell, 1993 
Purnomo, David Pan, Menjawab Pertanyaan-pertanyaan Kontemporer.Malang: SAAT, 2001

Ruth F.Selan, Wanita Kristen dalam Mengatasi Pergumulan Hidup. Bandung: Kalam Hidup, 1993

Stott, John, Issues Facing Christians Today: New Perspectives on Social and Moral Dilemmas. London: Marshall Pickering, 1990.

Trull, Joe.E. dan carter, James E., Menjaga Integritas dalam Pelayanan Tantangan Berat Pelayanan Gereja. Jakarta: BPK Gunung Mulia, 2012 